\title{
Correction to: Measuring Trends in Urban Inequality and Poverty in the Copperbelt, Zambia
}

\author{
Owen Crankshaw $^{1}$ - Jacqueline Borel-Saladin ${ }^{2}$
}

Published online: 13 November 2017

(C) Springer Science+Business Media B.V. 2017

\section{Correction to: Urban Forum \\ https://doi.org/10.1007/s12132-017-9319-y}

The original version of this article unfortunately contained a mistake.

The Fig. 5 image was published erroneously.

The corrected Fig. 5 is shown in the next page. The original article was corrected.

The online version of the original article can be found at https://doi.org/10.1007/s12132-017-9319-y.

Jacqueline Borel-Saladin

Jacqueline.Borel-Saladin@uct.ac.za

Owen Crankshaw

owen.crankshaw@uct.ac.za

1 Sociology Department, University of Cape Town, Private Bag X3, Rondebosch 7701, South Africa

2 African Centre for Cities, University of Cape Town, Private Bag X3, Rondebosch 7701, South Africa 


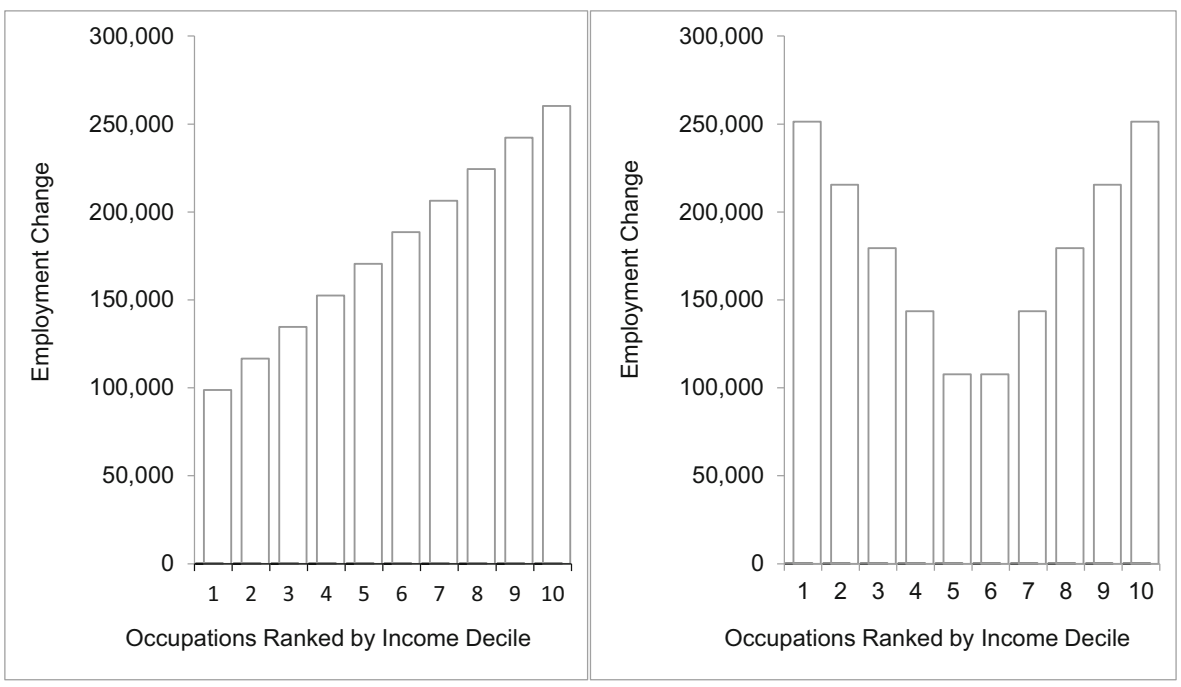

Uni-Modal Distribution

Bi-Modal Distribution

Fig. 5 Uni-modal and bi-modal distributions of employment change by income-ranked occupations 